2015-11-01

\title{
Strength Training and Body Composition in Middle-Age Women
}

Rachelle Burrup

Brigham Young University

Follow this and additional works at: https://scholarsarchive.byu.edu/etd

Part of the Exercise Science Commons

\section{BYU ScholarsArchive Citation}

Burrup, Rachelle, "Strength Training and Body Composition in Middle-Age Women" (2015). All Theses and Dissertations. 6162. https://scholarsarchive.byu.edu/etd/6162

This Thesis is brought to you for free and open access by BYU ScholarsArchive. It has been accepted for inclusion in All Theses and Dissertations by an authorized administrator of BYU ScholarsArchive. For more information, please contact scholarsarchive@byu.edu, ellen_amatangelo@byu.edu. 
Strength Training and Body Composition in Middle-Age Women

Rachelle Burrup

A thesis submitted to the faculty of

Brigham Young University

in partial fulfillment of the requirements for the degree of

Master of Science

Larry A. Tucker, Chair

James D. LeCheminant

Bruce W. Bailey

Department of Exercise Sciences

Brigham Young University

November 2015

Copyright (C) 2015 Rachelle Burrup

All Rights Reserved 


\author{
ABSTRACT \\ Strength Training and Body Composition in Middle-Age Women \\ Rachelle Burrup \\ Department of Exercise Sciences, BYU \\ Master of Science
}

OBJECTIVE: The purpose of this study was to examine the relationship between strength training and body composition before and after controlling for several covariates. A crosssectional study including 257 female subjects was conducted. METHODS: Subjects' level of involvement in strength training was determined via questionnaire. Body composition was assessed using dual energy X-ray absorptiometry (DXA). Diet was assessed using 7-d weighed food records. RESULTS: Strong linear relationships between subjects' level of involvement in strength training and body composition were identified. For each additional day of strength training reported per week, body fat was 1.32 percentage points lower $(\mathrm{F}=14.8, p=0.0002)$ and fat-free mass was $656.4 \mathrm{~g}(1.45 \mathrm{lb})$ higher $(\mathrm{F}=18.9, p<0.0001)$, on average. Likewise, the more time subjects spent lifting and the more intensely they trained, the better their body composition tended to be. Adjusting for differences in age, menopause status, objectively measured physical activity, energy intake, and protein intake tended to weaken each association. Controlling for differences in physical activity weakened each relationship the most. CONCLUSION: Women who strength train regularly tend to have significantly lower body fat percentages and significantly higher levels of fat-free mass compared to their counterparts, regardless of differences in several potential confounding variables.

Keywords: weight lifting, resistance training, body fat, exercise, protein, fitness 


\section{ACKNOWLEDGMENTS}

I would like to express sincere appreciation to the following individuals for their support, suggestions, and overall investment in this project: Dr. James LeCheminant, Dr. Bruce Bailey, and Dr. Larry Tucker. To Dr. Tucker I would like to express my overwhelming gratitude to him for taking me on as a graduate student and making this degree a reality for me. His mentorship has been an invaluable part of my education. His passion for research and health will always inspire me. It has been an honor to work with him.

The BYU Exercise Sciences Department has created many opportunities for me to expand my knowledge in a field I love. I am grateful to BYU and this department for providing these experiences that encouraged me to continue learning.

I would also like to acknowledge friends and family who have supported and believed in me throughout this process. Their prayers and words of encouragement kept me moving forward. I am especially grateful to my parents for teaching me the value of hard work, dedication, and a love for learning. They are the champions in my life. Their unfailing confidence in my abilities and gentle words of wisdom have been a constant in my life and have taught me to dream, which I will be forever grateful for. 


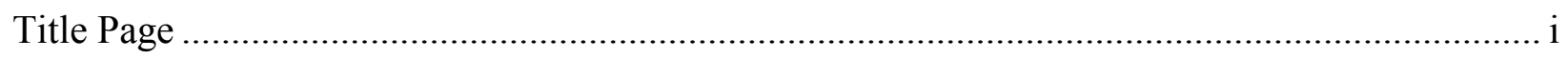

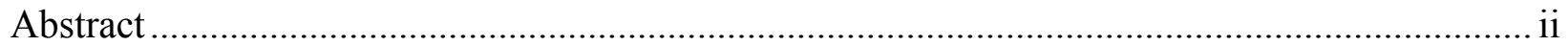

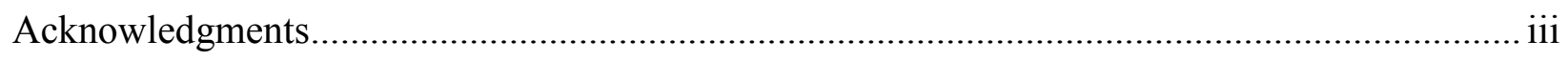

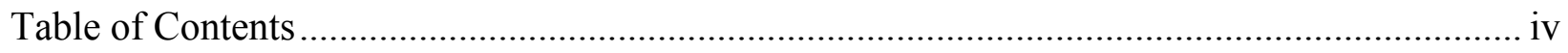

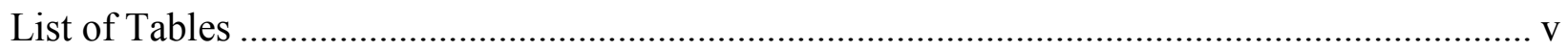

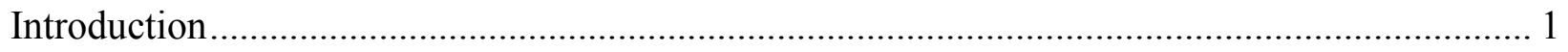

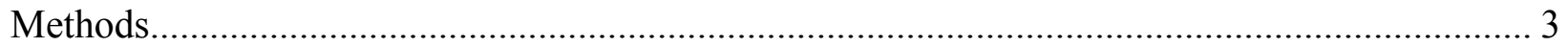

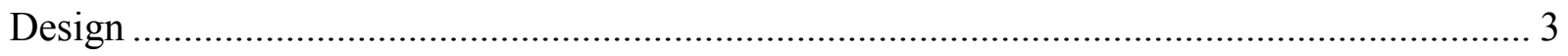

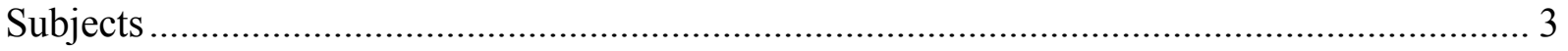

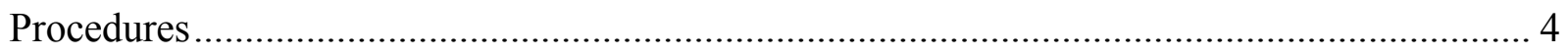

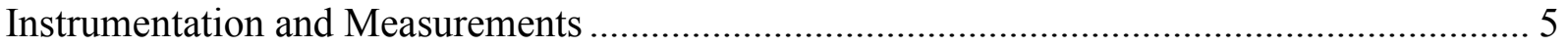

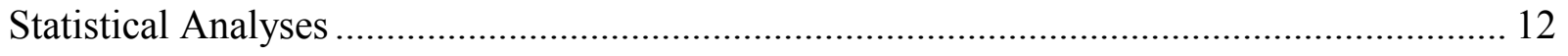

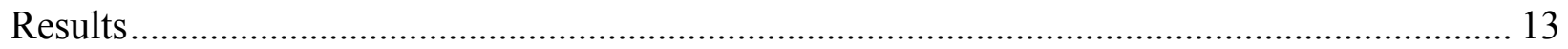

Days per Week of Strength Training and Body Composition ................................................ 13

Minutes per Strength Training Session and Body Composition.............................................. 14

Total Time Spent Strength Training per Week and Body Composition................................... 15

Consecutive Years of Strength Training and Body Composition............................................ 16

Intensity of Strength Training Sessions and Body Composition ............................................ 17

Body Composition and the Covariates ……………….................................................... 17

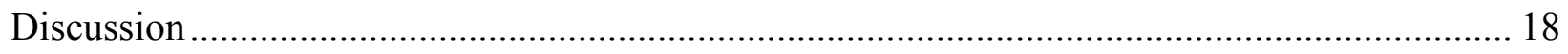

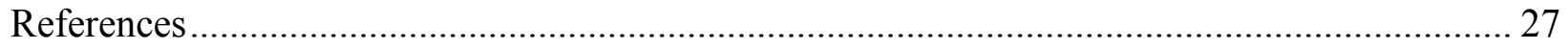




\section{List of Tables}

Table 1 Descriptive statistics between all subjects and mean differences between Lifters and

Nonlifters

Table 2 Differences in body fat percentage and fat-free mass corresponding to a 1-day-per-week difference in strength training, independent of key potential confounding variables $(n=257)$

Table 3 Differences in body fat percentage and fat-free mass corresponding to a 10-min difference in total time spent strength training per session, independent of key potential confounding variables $(\mathrm{n}=257)$

Table 4 Differences in body fat percentage and fat-free mass corresponding to a 10 -min difference in total time spent strength training per week, independent of key potential confounding variables $(\mathrm{n}=257)$

Table 5 Differences in body fat percentage and fat-free mass corresponding to a $1 \mathrm{y}$ difference in years of continuous strength training, independent of key potential confounding variables (n $=257)$.

Table 6 Differences in body fat percentage and fat-free mass corresponding to a 1-unit difference in intensity of strength training sessions, independent of key potential confounding variables $(\mathrm{n}=257)$. 44 


\section{Introduction}

The American College of Sports Medicine (ACSM) defines body composition as "the relative proportion of fat and fat-free tissue in the body (percent body fat)." ${ }^{\prime 1}$ Both fat mass and fat-free mass are independent predictors of disease risk. Unfortunately, as adults age, their body composition tends to change detrimentally_-body fat tends to increase, ${ }^{2}$ and fat-free mass tends to decrease. ${ }^{2,3}$

Excess levels of body fat increase morbidity and mortality risk significantly. ${ }^{4-6}$ Multiple studies have identified an association between high body fat and cardiovascular disease..$^{2,6,7}$ Additionally, high levels of body fat tend to predict increased risk for the metabolic syndrome, ${ }^{6}$ osteoporosis, insulin resistance, and decreased quality of life. ${ }^{2}$

A low level of fat-free mass is an indicator of poor health and greater risk of disease. Findings from several studies indicate an inverse association between fat-free mass and cardiovascular disease risk. ${ }^{8-11}$ Research by Fletcher et al. ${ }^{12}$ and Klein et al. ${ }^{13}$ noted a relationship between low levels of muscle mass and increased risk for dyslipidemia, hypertension, obesity, insulin resistance, and type 2 diabetes.

Because declining levels of fat-free mass typically accompany aging, ${ }^{3}$ risk is pervasive. Age-related decreases in muscle mass are known as sarcopenia. ${ }^{2}$ Sarcopenia affects women more than men $^{7}$ and is related to inactivity and disease. ${ }^{14}$ Individuals with sarcopenia tend to have higher levels of oxidative stress, inflammation, insulin resistance, and decreased muscular strength. ${ }^{15}$

To prevent or lessen adverse age-related changes in body composition, interventions focused on increasing fat-free mass and decreasing fat mass are needed. This may best be 
accomplished by strength training. Strength training may halt or attenuate rising body fat levels ${ }^{16-18}$ and increase fat-free body mass. ${ }^{16,19-21}$

Although high body fat levels and sarcopenia are more prominent in women, research indicates that women are less likely to participate in regular weight lifting than men. ${ }^{22}$ Moreover, a vast majority of the research investigating the relationship between resistance training and body composition has been performed in men. ${ }^{2,16,23-25}$

Most studies investigating the relationship between strength training and body composition in women have been relatively short in duration, between 3 and 6 months, on average. ${ }^{23,24,26-34}$ Long-term studies ( $>1 \mathrm{y}$ ) are rare, and compliance seems to be a problem over time. $^{35-37}$

Because body fat tends to increase and fat-free mass tends to decrease in women as they age, national guidelines encourage women to strength train regularly. ${ }^{21,38}$ However, many questions about the effects of strength training on women remain unanswered. For example, does long-term training with weights continue to improve body composition in women, even after years of lifting? Does protein intake in women influence the benefits derived from strength training? To what degree does cardiorespiratory exercise affect body composition changes associated with strength training? Is strength training 3 or $4 \mathrm{~d}$ per week more beneficial for body composition changes compared to lifting 1 or $2 \mathrm{~d}$ per week? How intensely do women have to train with weights to derive worthwhile changes in body composition?

The present study was designed to answer these questions associated with strength training and body composition. Specifically, the primary objective was to determine the extent to which minutes per week of strength training, and years of training with weights in the past, are predictive of body fat and fat-free mass in 257 middle-age women. The extent to which 
differences in body composition are associated with the number of days per week of strength training and the intensity of that exercise were also examined. Additional objectives were to quantify the effect of age, menopause status, objectively measured physical activity, energy consumption, and protein intake, considered individually and in combination, on the relationship between strength training and body composition, including fat and fat-free mass, in women.

\section{Methods}

\section{Design}

The present study employed a cross-sectional design. Subjects were asked to report historical and current information about their participation in strength training. The strength training data were used to account for differences in current body composition in participants. Age, menopause status, total energy intake, protein consumption, and objectively measured physical activity were measured, and their influence on the relationship between strength training and body composition was evaluated. Data were gathered from 2001-2002.

\section{Subjects}

A total of 257 female subjects participated in the present study. Participation criteria included the following: must be a nonsmoker, female, nonpregnant, $>35$ and $<50$ y old, and apparently healthy based on subjects' responses to a physical activity readiness questionnaire (PAR-Q). All subjects were screened via a telephone interview. Prior to the start of the study, each subject signed an informed consent, approved by the University's Institutional Review Board. Recruitment of subjects included the use of flyers, advertisements, and email. Subjects were recruited from two metropolitan areas of the Mountain West. 


\section{Procedures}

All subject information and measurements were collected at the University's Human Performance Research Center. Measurements such as height, weight, and body composition were measured once during the study while subjects were wearing a university-issued one-piece swimsuit. Dual energy X-ray absorptiometry (DXA), with a Hologic QDR 4500 W (Waltham, MA), was used to estimate body fat percentage and fat-free mass. Prior to performing any scans for the day, the DXA equipment was calibrated. Subjects' body composition was evaluated and body fat percentage was estimated using Hologic's scan software.

Each subject was required to wear an accelerometer and complete a weighed food record for 7 consecutive days. Subjects were instructed to avoid changing their exercise or dietary habits throughout the recording period. An Actigraph accelerometer, model 7164 (Health One Technology, Pensacola, FL) and digital food scale (Ohaus 2000, Florham Park, NJ) were issued to each participant so that habitual physical activity and dietary patterns could be assessed. Physical activity and dietary habits were assessed once during the study, each during the same 7d period.

Participants were instructed to wear the activity monitor over the left hip. The activity monitor was to be worn continuously, except during water activities. Subjects were carefully instructed on how to appropriately wear the accelerometer. Beginning a new exercise program during the 7-d period was prohibited.

Study personnel instructed subjects on how to use the digital food scale through written instruction and demonstration with plastic food models. Participants were also shown examples of common recording errors to improve record detail, accuracy, and compliance. A packet including written instructions, blank log forms, and a sample record was given to subjects. 
Subject agreement in maintaining normal physical activity and dietary intake patterns was verified and procedural questions were asked during a phone call to each subject during the week of recording. At the conclusion of the $7 \mathrm{~d}$, the food scale, food record, and accelerometer were returned and subjects were weighed again, following the same protocol. A \$25 gift certificate and thank you letter were mailed to subjects once their data were verified as complete and accurate.

\section{Instrumentation and Measurements}

The following variables were included in the present study: age, objectively measured total physical activity, total energy intake, percent of energy derived from dietary protein, menopause status, body fat percentage, fat-free body mass, muscular strength and/or endurance (leg power, sit-up, and bench press assessments), and level of involvement in strength training: days per week of strength training, minutes of training per session, total time spent strength training per week, consecutive years of involvement in strength training, and intensity of strength training sessions.

Physical Activity. Habitual physical activity was evaluated using Actigraph accelerometers, model 7164 (Health One Technology, Pensacola, FL). Accelerometers were worn over the left hip for 7 consecutive days in order to index activity each day of the week and the weekend, as performed in previous studies. ${ }^{39,40}$ At the conclusion of the 7 -d period, accelerometers were returned to study personnel and activity data were downloaded and reviewed for accuracy. Subject compliance was based on a minimum of $12 \mathrm{~h}$ of wear time during the waking hours per day. Nonwear time was defined as a string of 10 or more min of zeros. If records showed less than $12 \mathrm{~h}$ of wear time during the waking hours for any of the $7 \mathrm{~d}$, subjects were asked to rewear the accelerometer. This time, however, the accelerometer was only worn 
on the subject's corresponding, nonwear day(s) of the week. Removal of the accelerometer was permitted only during water activities, such as showering and swimming. Mean wear time was $13.9 \mathrm{~h}$ between 7 A.M. and 10 P.M. During those $15 \mathrm{~h}$, subjects wore the accelerometer $93 \%$ of the time throughout the 7-d period. The wear-time standards employed in the current study exceeded the wear-time criteria used in other research. ${ }^{41-43}$

One advantage of using activity monitors is that they provide an objective assessment of habitual physical activity. Accelerometry reduces error due to subject recall bias, making this method superior to self-reported physical activity records. ${ }^{44}$ The validity ${ }^{45,46}$ and reliability ${ }^{47}$ of the Actigraph accelerometer offers additional advantages. In a study by Liu et al., ${ }^{45}$ Actigraph recorded activity counts were compared to subjects' total energy expenditure measured concurrently using doubly labeled water. A significant relationship was found between the Actigraph accelerometer counts and the doubly labeled water measurements of total energy expenditure $(\mathrm{r}=0.31, p<0.01)$. The validity of Actigraph accelerometers was further supported in a study by Basset et al. ${ }^{46}$ In comparison to three other motion sensors investigated, the Actigraph accelerometer demonstrated a much stronger correlation with direct calorimetry measurements $(r=0.62, p=0.0473)$. The excellent reliability of the Actigraph accelerometer was demonstrated in another study when an intraclass correlation coefficient of 0.80 was identified. ${ }^{47}$ In summary, Actigraph accelerometers are a valid, reliable, and frequently used method for assessing physical activity objectively in adults. ${ }^{44-48}$

Total Energy Intake. To measure total energy intake, 7-d weighed food records were used. Weighed food records directly measure dietary intake, thereby limiting subject recall bias and eliminating portion-size measurement error. ${ }^{49,50}$ By requiring subjects to keep a record for 7 d, typical dietary patterns throughout the week were captured. ${ }^{49}$ 
A digital food scale (Ohaus 2000, Florham Park, NJ) was issued to each subject. Study personnel trained subjects on how to properly use the scale and record food and beverage consumption using printed instructions and plastic food models. Records were reviewed for accuracy and then entered into the ESHA Research software (ESHA Research Inc., Salem, OR) by a registered dietician.

To ensure that subjects did not restrict, change, or underreport their intake, study personnel contacted subjects during the recording period. Subjects were told that they would be weighed at the beginning and end of the $7 \mathrm{~d}$ to ensure that normal dietary habits did not change throughout the measurement period. Records with an energy intake less than $130 \%$ of a subject's estimated resting metabolic rate were considered insufficient on the premise of underreporting or restriction of food intake by the subject. ${ }^{51}$ These subjects were asked to complete a weighed food record for another $7 \mathrm{~d}$. Subjects' resting metabolic rates were determined using the Ravussin formula. $^{52}$

Protein Intake. Protein intake, expressed relative to a subject's total energy intake, was evaluated using participants' 7-d weighed food records. The percent of energy derived from dietary protein was determined by measuring the total grams of protein consumed, multiplying by 16.4 (protein provides approximately $16.4 \mathrm{~kJ}$ per gram consumed), and then dividing by the total number of $\mathrm{kJ}$ consumed.

Menopause Status. Subjects were asked six questions in order to establish menopause status. The menopause questionnaire has been validated in a previous study ${ }^{53}$ using a blood test that analyzed follicle-stimulating hormone levels (FSH). A statistically significant relationship was found between FSH levels and menopause status $\left(F=52.3, \mathrm{R}^{2}=0.45, p<0.0001\right)$, 
demonstrating concurrent validity of the menopause variable. FSH levels are an objective indication of menstrual activity or lack thereof.

Information collected from these questions was used to group subjects under the following categories: premenopausal $(n=138)$, perimenopausal $(n=34)$, and postmenopausal $(n$ $=35$ ). The presence of common menstrual symptoms, amount of time from the individual's last menstrual cycle, and regularity of menstrual cycles were emphasized.

Body Fat Percentage and Fat-Free Mass. Body fat percentage and fat-free mass were estimated using dual energy X-ray absorptiometry or DXA (Hologic QDR 4500w, Waltham, MA). While lying in a supine position, a whole-body scan was taken of each subject. The composition of soft tissue in subjects was estimated using the QDR 11.2 scan software (Hologic, Waltham, MA).

DXA has been identified as a safe and precise measurement method for estimating soft tissue composition. ${ }^{54-59}$ During the scan, subjects are exposed to minimal amounts of radiation. ${ }^{54}$ Unlike other body composition techniques, DXA assessments are not dependent on additional anthropometric measurements, like skinfold thickness or height and weight. Consequently, DXA measurements have shown greater precision than underwater weighing and skinfold caliper estimates. $^{55}$

Research by Mazess et al. identified a precision error of $<1.5 \%$ for total body fat percent and a $\sim 1.5 \%$ error when estimating lean tissue mass for the entire body. ${ }^{56}$ Other methods used for assessing body composition have reported comparable or larger precision errors. ${ }^{60}$ The direct method of assessment provided by DXA scans also limits potential inaccuracies in measurements or misclassification of body composition, which may be found in self-reported or measured body mass index (BMI) estimates. ${ }^{61}$ 
DXA estimates of body composition have been shown to correlate strongly with Bod Pod estimates of body composition, indicating concurrent validity ${ }^{57}$ In a study by Maddalozzo et al., ${ }^{57}$ a bivariate correlation of 0.89 (shared variance of $79.2 \%, p<0.01$ ) was identified between both techniques. Mean scores were not significantly different $(t=0.80, p>0.40)$ and a small observed difference score of $d=0.12$ was reported. Concurrent validity of the DXA and Bod Pod measurements was shown in another study comparing body composition measurements in 100 women. ${ }^{62}$ In the above study, comparison of the Bod Pod and DXA assessments resulted in an intraclass correlation of $0.97(p<0.001)$.

Strength Training. Subjects' participation in strength training was assessed using a series of questions. The questions inquired about the participant's current strength training habits and historical involvement; specifically, the number of days per week of strength training (STdays); minutes spent strength training per session (STmin); total time spent strength training per week (STwk); years of previous involvement in strength training (STyrs); and intensity of sessions (STint). STwk was calculated by multiplying the number of days per week subjects reported strength training regularly by the minutes spent training per session (STwk $=$ STdays $*$ STmin). To determine STint, subjects were asked how hard they push themselves while strength training. Participants were asked to rate the typical intensity of their strength training workouts on a 7point Likert scale. Possible responses ranged from "very easy" to "extremely hard." Subjects who reported lifting weights regularly, at least once a week or more, were categorized as Lifters. Those who indicated that they do not strength train at least once a week were considered Nonlifters. 
Muscular Strength, Endurance, and Power. Sit-up, bench press, and jumping tests were administered to each subject to validate responses to the strength training questions. A brief description of each test is provided below.

Sit-ups: Muscular strength and endurance in the lower trunk were measured using a sit-up test. For this evaluation, subjects performed as many sit-ups as possible in $60 \mathrm{~s}$. Palms were placed over the ears and cheeks with the elbows pointing directly ahead while the subject was lying supine. Knees were flexed so that the heels were $30-40 \mathrm{~cm}$ from the gluteus maximus. A test administrator held subject's feet in place on the mat. During the test, the upper body was raised off of the mat until the elbows touched the thighs. Before sitting up again, the subject's back had to touch the mat and the gluteus maximus had to remain on the mat throughout the entire range of motion. One advantage to using this particular test is normative values are easily accessible because multiple studies have previously used this method to assess hip-flexor and abdominal fitness. ${ }^{63}$

Bench Press: To evaluate muscular strength and endurance of the shoulder and chest muscles, a bench press test was used. The test was performed on a Universal (Gladiator Model, Universal Athletic Sales Co., Fresno, CA) bench press machine. To warm-up, participants performed one set of modified push-ups with their knees on the floor. During the test, weight was lifted until full extension of the arms and then returned to the starting position with the arms flexed. All repetitions were performed continuously with no rest between repetitions. Termination of the test occurred when subjects could not perform another repetition.

To standardize this test, participants lifted $35 \%$ of their body weight. As a result, each subject was assessed in proportion to her body mass. Using this method eliminates the disadvantage lighter participants experience during a normal bench press test with a set weight. 
Lifting $35 \%$ of the subject's body weight has been validated in pilot testing and published research. ${ }^{64}$ Overall, the bench press test has been identified in the literature as an appropriate method for assessing muscular strength and endurance of the shoulder and chest muscles. ${ }^{65}$

Average Vertical Jump: A “Just Jump” (Probotics, Huntsville, AL) mat was used to measure the jumping height of each subject, an index of leg power. Prior to the assessment, subjects were asked to perform a few jumps while a test administrator corrected poor form. Subjects were instructed to jump as high as possible while not using their arms. Arms were to remain down at the subject's sides throughout the test. Legs were extended with the heels away from the gluteus maximus during each jump. Subjects were given five attempts to jump as high as possible with a $15-30 \mathrm{~s}$ rest in between. The average of the five jumps was used to index leg power. According to research, the Just Jump mat is considered a valid method for assessing jump height and is comparable to the three-camera system. ${ }^{66}$

Performance on the three tests was strongly related to responses on the strength training questions, providing solid evidence of concurrent validity. Specifically, STdays was directly related to performance on the bench press test. For each additional day of strength training per week reported, the number of repetitions performed on the bench press increased by $4.8(\mathrm{~F}=$ $59.8, p<0.0001)$. On the sit-up test, for each additional day of strength training, participants performed an additional 1.8 sit-ups $(\mathrm{F}=19.7, p<0.0001)$, and for each additional day of strength training reported, on average, the women jumped $1.0 \mathrm{~cm}$ higher $(\mathrm{F}=16.4, p<0.0001)$. Similar results were identified on the other strength training variables. Greater self-reported participation in strength training was highly predictive of greater muscular strength, endurance, and power in the women, suggesting that the strength training questionnaire was valid and actually measured subjects' participation in strength training. 


\section{Statistical Analyses}

Using the PASS 6.0 statistical software (NCSS, Kaysville, UT), a power analysis was conducted to determine the number of subjects needed to detect a correlation of $0.20\left(R^{2}=0.04\right)$ using multiple regression with alpha set at 0.05 . The analysis showed that 254 subjects were necessary to achieve 0.90 power. Hence, the sample size of the present study $(n=257)$ was sufficient for the needs of this study.

Regression analysis using the General Linear Model (GLM) procedure was employed to determine the relationship between each of the strength training variables, including STdays, STint, STmin, STwk, and STyrs, and body composition, specifically body fat percentage and fatfree body mass. Partial correlation was used to determine the extent to which the relationship between each index of strength training participation and body composition was influenced by the potential confounders. Specifically, adjusted regression coefficients were reported to show the effect of differences in age, menopause status, energy intake, physical activity, and protein consumption, considered individually and as a composite, on the strength training and body composition associations. The extent to which the relationships were strengthened or weakened by the covariates was calculated using the percentage increase or decrease in shared variance with and without statistical control for the potential confounder(s). More specifically, the difference in the Type I sum of squares before and after controlling for a covariate was divided by the Type I sum of squares value when the covariate was not controlled. All 257 subjects were included in each analysis. Alpha was set at the 0.05 level and the SAS (SAS Institute, Cary, NC) software program (version 9.3) was utilized for all of the analysis. 


\section{Results}

Of the 257 women in the study, average $( \pm \mathrm{SD})$ age was $41.7 \pm 3.0 \mathrm{y}$ and mean body fat percentage was $32.3 \pm 7.2$. On average, participants weighed $64.8 \pm 10.5 \mathrm{~kg}$ and consumed 1975 $\pm 316 \mathrm{kcal}$ per day. A majority of the sample was married (83\%) and approximately $90 \%$ were Caucasian. Approximately 58\% of the participants reported working part- or full-time. A total of $39 \%$ indicated that they were a college graduate.

A total of 109 participants reported involvement in muscle strengthening activities at least once per week (Lifters), and 148 indicated that they did not strength train regularly (Nonlifters). Specifically, 11 women reported that they lifted $1 \mathrm{~d}$ per week, 40 reported $2 \mathrm{~d}$ per week, 42 indicated $3 \mathrm{~d}$ per week, and 16 reported lifting 4 or more d per week. Among Lifters, average $( \pm \mathrm{SD})$ body fat percentage was $30.1 \pm 6.8$, and for Nonlifters it was $34.0 \pm 7.1(\mathrm{~F}=$ $19.3, p<0.0001)$. Average protein intake $(\%$ of total energy intake) for Lifters and Nonlifters was $15.0 \pm 3.3$ and $14.1 \pm 2.7(\mathrm{~F}=5.7, p=0.0181)$, respectively. Average age was $41.6 \pm 3.0$ and $41.7 \pm 3.0(\mathrm{~F}=0.1, p=0.7505)$ for the Lifters and Nonlifters, respectively. Descriptive statistics for the entire sample and mean differences between Lifters and Nonlifters are displayed in Table 1.

Linear regression coefficients describing the relationship between each index of strength training and body composition, with and without controlling for potential confounders, are displayed in Tables 2-6. Age, menopause status, total energy intake, physical activity, and protein intake were controlled separately and also in combination, as shown in Tables 2-6. Days per Week of Strength Training and Body Composition

As shown in Table 2, with no variables controlled statistically, for each additional day of strength training per week reported by the women $(n=257)$, body fat was 1.32 percentage points 
lower, on average $(\mathrm{F}=14.8, p=0.0002)$. After adjusting for all of the potential confounders simultaneously, including age, menopause status, energy intake, physical activity, and protein consumption, body fat was 0.85 percentage point lower for each additional day of strength training $(\mathrm{F}=8.3, p=0.0044)$. None of the covariates strengthened the correlation and none weakened it to the point of nonsignificance. However, adjusting for differences in objectively measured physical activity changed the relationship most, weakening it by approximately $66 \%$ $(\mathrm{F}=5.5, p=0.0196)$. As mentioned in the Methods section, the weakening of this relationship was determined by calculating the percent change in shared variance (i.e., Type I sum of squares).

The relationship between days per week of strength training and fat-free mass was also statistically significant, with and without controlling for the potential confounders, as shown in Table 2. With no variable controlled statistically, fat-free mass increased by $656.4 \mathrm{~g}(1.45 \mathrm{lb})$ for each additional day of strength training reported per week $(\mathrm{F}=18.9, p<0.0001)$. Only one covariate strengthened the association, energy intake, and it was minimal. None of the covariates weakened the relationship to nonsignificance. Again, controlling for differences in physical activity weakened the relationship most, approximately $53 \%(\mathrm{~F}=9.3, p=0.0025)$. After adjusting for all of the covariates simultaneously, $443.3 \mathrm{~g}(0.98 \mathrm{lb})$ higher fat-free mass was observed for each reported additional day of strength training per week $(\mathrm{F}=8.3, p=0.0044)$. Minutes per Strength Training Session and Body Composition

Table 3 displays the relationship between self-reported minutes per strength training session and body composition. The association was statistically significant with and without adjusting for the potential confounders. When no variables were controlled statistically, body fat was 0.96 percentage point lower for each 10 -min increment per strength training session $(\mathrm{F}=$ 
19.6, $p<0.0001)$. When all of the covariates were controlled simultaneously, the link between minutes per strength training session and body fat percentage was weakened by approximately $68 \%(\mathrm{~F}=10.0, p=0.0018)$. Specifically, for each $10-\mathrm{min}$ increment in time spent strength training per session, body fat was 0.59 percentage point lower among participants, on average, after adjusting for differences in age, menopause status, total energy intake, physical activity, and protein consumption. Adjusting for differences in protein intake strengthened the relationship slightly, whereas the other covariates tended to weaken the link, but none to the point of nonsignificance.

Fat-free mass was $413.9 \mathrm{~g}(0.91 \mathrm{lb})$ higher, on average, for every 10-min increase in duration of training sessions, when no variables were controlled statistically $(\mathrm{F}=18.1, p<$ 0.0001). When all of the potential confounders were controlled simultaneously, an increase of $272.4 \mathrm{~g}(0.60 \mathrm{lb})$ of fat-free mass was observed for each additional $10 \mathrm{~min}$ of strength training per session $(\mathrm{F}=7.9, p=0.0054)$.

\section{Total Time Spent Strength Training per Week and Body Composition}

The associations between total time spent strength training per week (days per week $x$ minutes per training session) and body composition were statistically significant, without and with controlling for the covariates (Table 4). With no adjustments for the potential confounders, for each additional $10 \mathrm{~min}$ of total lifting time per week, body fat percentage was 0.34 percentage point lower $(\mathrm{F}=14.3, p=0.0002)$. This relationship was weakened after adjusting for differences in age, menopause status, energy intake, and physical activity, particularly the latter, which weakened the association by $54 \%$. The only potential confounder that strengthened the relationship was protein intake. After adjusting for differences in all of the potential confounders 
together, for each additional 10 min of time spent strength training per week, body fat was 0.20 percentage point lower, on average $(\mathrm{F}=6.7, p=0.0103)$.

For every 10 -min increment in total-time spent strength training per week, fat-free mass was $157.4 \mathrm{~g}(0.35 \mathrm{lb})$ higher, on average, with no variables controlled statistically $(\mathrm{F}=16.2, p<$ 0.0001). The association was weakened after adjusting individually for differences in age, menopause status, energy consumption, physical activity, and protein intake. Again, controlling for differences in physical activity alone weakened the correlation most, approximately $45 \%(\mathrm{~F}=$ $9.5, p=0.0023$ ). After adjusting for differences in all of the covariates simultaneously, a $101.3 \mathrm{~g}$ $(0.22 \mathrm{lb})$ increase in fat-free mass was observed for each 10 -min increment in total-time spent strength training per week $(\mathrm{F}=6.5, p=0.0111)$.

\section{Consecutive Years of Strength Training and Body Composition}

Table 5 displays the relationship between consecutive years of strength training and body composition. For each additional year of strength training reported, body fat was 0.65 percentage point lower, on average, when no confounders were adjusted for $(\mathrm{F}=10.4, p=0.0015)$. Controlling for differences in objectively measured physical activity weakened the association by $68 \%$, resulting in borderline significance $(\mathrm{F}=3.6, p=0.0582)$. After adjusting for all of the covariates simultaneously, body fat was 0.41 percentage point lower for each additional consecutive year of strength training $(\mathrm{F}=6.0, p=0.0147)$.

With no potential confounders controlled, fat-free mass increased by $270.1 \mathrm{~g}(0.59 \mathrm{lb})$ for each additional year of strength training reported by participants $(\mathrm{F}=9.1, p=0.0029)$. One variable, energy intake, strengthened the association marginally. Age, menopause status, energy intake, physical activity, and protein consumption each weakened the relationship. However, adjusting for differences in physical activity weakened the correlation by $64 \%$, resulting in a 
borderline significant association $(\mathrm{F}=3.5, p=0.0633)$. After controlling for all of the covariates together, for each additional year of reported strength training, fat-free mass was $169.6 \mathrm{~g}(0.37$ lb) higher, on average, and the relationship was borderline significant $(\mathrm{F}=3.8, p=0.0523)$. Intensity of Strength Training Sessions and Body Composition

As shown in Table 6, with no variables controlled statistically, for every 1-unit increase in self-reported intensity of strength training, there was a 0.57 percentage point decrease in body fat $(\mathrm{F}=21.4, p<0.0001)$. All of the covariates, except protein intake, weakened the relationship. Again, controlling for differences in physical activity changed the correlation most, weakening it by $54 \%$. After adjusting for differences in all of the potential confounders simultaneously, body fat was 0.38 percentage point lower for every 1 -unit increase in self-reported training intensity ( $\mathrm{F}$ $=12.4, p=0.0005)$.

Similarly, when no variables were controlled statistically, fat-free mass was $280.0 \mathrm{~g}(0.62$ lb) higher for every 1 -unit increase in strength training intensity $(\mathrm{F}=26.7, p<0.0001)$. Individually adjusting for differences in physical activity had the largest effect on the association, weakening it by $44 \%$. However, the relationship remained highly significant ( $\mathrm{F}=$ $15.9, p<0.0001)$. After adjusting for all of the potential confounders together, fat-free mass was $200.8 \mathrm{~g}(0.44 \mathrm{lb})$ higher for every 1 -unit increase in strength training intensity $(\mathrm{F}=13.1, p=$ $0.0004)$.

\section{Body Composition and the Covariates}

Most of the potential confounding variables were predictive of body composition in the present study. For age, each additional year was associated with 0.3 percentage point higher body fat in the sample of middle-age women $(\mathrm{F}=4.6, p=0.0326)$. Additionally, premenopausal women had 3.5 percentage points lower body fat than their peri- and postmenopausal 
counterparts $(\mathrm{F}=12.1, p=0.0006)$. This relationship was only weakened slightly after adjusting for differences in age $(\mathrm{F}=10.5, p=0.0013)$. For objectively measured physical activity, with each additional 100,000 activity counts, equal to approximately 25 min of walking, ${ }^{41-43}$ body fat was 0.3 percentage point lower $(\mathrm{F}=33.9, p<0.0001)$. Protein intake expressed as a percent of total energy intake was not associated with body fat percentage $(\mathrm{F}=0.2, p=0.6713)$.

In general, the relationships between fat-free mass and the covariates were weaker than the associations between body fat percentage and the potential confounders. In each case, body weight was controlled statistically. Otherwise, high fat-free mass would simply represent high body mass. For age, the relationship was inverse and borderline significant $(\mathrm{F}=3.6, p=0.0592)$. However, menopause status was related to fat-free mass $(\mathrm{F}=8.9, p=0.0031)$. Premenopausal women had $1.3 \mathrm{~kg}$ more fat-free mass than their peri- and postmenopausal counterparts, given the same body weight. Adjusting for age weakened the relationship by $14 \%$, but it remained highly significant $(\mathrm{F}=7.7, p=0.0058)$. For physical activity, each additional 100,000 counts was associated with $0.1 \mathrm{~kg}$ higher fat-free mass $(\mathrm{F}=26.7, p<0.0001)$. Protein intake was not associated with fat-free mass in the women, after controlling for differences in body weight ( $\mathrm{F}=$ $1.2, p=0.2773)$.

\section{Discussion}

The present investigation identified several significant relationships between level of involvement in strength training and body composition in middle-aged women. Particularly, the more frequently and intensely women engaged in strength training, the lower their body fat percentage tended to be (Tables 2 and 6). Furthermore, results showed that the more time women participated in strength training, indexed as total time per week, minutes per session, or past history of strength training in consecutive years, the lower their body fat percentage was, on 
average (Tables 3-5). The relationship between strength training and body fat percentage remained significant after controlling individually or in combination for differences in age, menopause status, total energy consumption, objectively measured physical activity, and protein intake.

A significant association was also revealed between each index of strength training and fat-free mass (Tables 2-6). The relationship between years of continuous involvement in strength training and fat-free mass was weakened to the point of nonsignificance, however, after adjusting for differences in total physical activity. Additionally, this relationship was weakened to the point of borderline significance after controlling for differences in all of the covariates together (Table 5).

According to the present findings, women who train regularly with weights tend to have significantly more fat-free mass and significantly lower body fat percentage than their counterparts. It appears that the more days per week women train, the better their body composition tends to be. Interpretation of the regression results indicates that women who strength train twice per week, consistent with the minimum U.S. recommendations, ${ }^{21,38}$ tend to have $1.3 \mathrm{~kg}(2.9 \mathrm{lb})$ more fat-free mass, after exclusively adjusting for differences in body mass, and 2.6 percentage points lower body fat compared to Nonlifters when no covariates are adjusted for. Likewise, women who train 3 or $4 \mathrm{~d}$ per week, on average, have $2.0(4.3 \mathrm{lb})$ to $2.6 \mathrm{~kg}(5.8 \mathrm{lb})$ higher fat-free mass and 3.9 to 5.2 percentage points lower body fat, respectively, compared to women who do not perform resistance training regularly. From a practical perspective, it seems that the number of days that women strength train per week plays a significant role in the body composition of women. 
Furthermore, according to the results of this investigation, women who spend more total time strength training per week tend to have significantly more muscle mass and significantly lower body fat percentage compared to women who spend less time lifting per week. For example, interpreting the regression findings indicates that women who spend a total of $60 \mathrm{~min}$ per week lifting tend to have $0.9 \mathrm{~kg}(2.1 \mathrm{lb})$ more fat-free mass, after solely controlling for differences in total body weight, and 1.8 percentage points lower body fat than Nonlifters when none of the covariates are controlled. Further interpretation shows that substantial involvement in strength training, lifting 2 to $3 \mathrm{~h}$ per week, is predictive of $1.9 \mathrm{~kg}(4.2 \mathrm{lb})$ to $2.8 \mathrm{~kg}(6.2 \mathrm{lb})$ of additional fat-free mass compared to Nonlifters and 3.6 to 5.4 percentage points lower body fat, respectively. Apparently, total time spent engaged in strength training per week contributes substantially to differences in body composition in women.

Number of minutes women train per session also seems to be predictive of differences in body composition in women. For example, converting the regression coefficient findings to practical outcomes indicates that women who work out resistively for $30 \mathrm{~min}$ at a time tend to have $1.2 \mathrm{~kg}(2.7 \mathrm{lb})$ higher fat-free mass and 3.0 percentage points lower body fat than those who do not strength train regularly when no covariates are controlled. Longer training sessions, such as $60 \mathrm{~min}$, correspond to $2.4 \mathrm{~kg}(5.5 \mathrm{lb})$ greater fat-free mass and 6.0 percentage points lower body fat compared to Nonlifters. Similarly, the lifting intensity findings indicate that as women lift at an increasingly greater intensity, body composition tends to improve linearly. In practical terms, women who report that they train "very hard" tend to have $1.7 \mathrm{~kg}(3.7 \mathrm{lb})$ higher fat-free mass and 3.6 percentage points lower body fat than women who report that they train "very easy." Clearly, the more time and the more effort women give to strength training, the better their body composition tends to be. 
Interpretation of the consecutive years of regular strength training findings also appears to differentiate among women's body composition. Compared to women who do not strength train, those who habitually lift weights for 3 to 5 consecutive years tend to have $0.8 \mathrm{~kg}(1.8 \mathrm{lb})$ to $1.4 \mathrm{~kg}(3.0 \mathrm{lb})$ higher fat-free mass, on average, and 1.8 to 3.0 percentage points lower body fat, respectively. Although less predictive than the other strength training variables, consecutive years of training appears to be a significant contributor to body composition differences, with more years associated with higher fat-free mass and lower body fat percentage.

Multiple studies have investigated the effect of strength training on body composition. However, few have actually quantified how age, menopause status, energy intake, protein consumption, and objectively measured physical activity influence the association. The present study measured and quantified the effect each of these potential confounders has on the relationship between weight lifting and body composition.

As individuals age, body composition tends to change detrimentally, leading to higher body fat ${ }^{3}$ and lower levels of fat-free mass. ${ }^{2,3}$ Additionally, hormonal changes occurring during menopause may exaggerate age-related fluctuations in body composition. ${ }^{67}$ In the present study, controlling for age weakened the association between each index of strength training and body composition minimally $(<1 \%)$. However, menopause status weakened each association by approximately $20 \%$, on average, but statistical significance remained in every case. These findings indicate that the relationship between weight lifting and body composition is not influenced significantly by differences in age, possibly because of the limited age-range of the present sample, but menopause status may play a role.

Energy consumption has a strong influence on body composition. ${ }^{68,69}$ Typically, as energy intake increases, body composition deteriorates. ${ }^{68,69}$ Controlling for total energy intake in 
the current investigation, however, did not affect the link between involvement in strength training and body composition. Overall, the associations were affected inconsistently, but none to the point of nonsignificance. Whether women consume ample or nominal amounts of total energy, the association between strength training and body composition does not seem to be influenced significantly.

Protein intake is believed to influence body composition ${ }^{70}$ especially when combined with strength training. ${ }^{71-74}$ In the present study, the associations between strength training and body fat percentage and strength training and fat-free mass were marginally weakened $(6 \%$ or less) by controlling for differences in protein intake. In a few instances, adjusting for differences in protein intake strengthened the relationship, but only minimally $(<1 \%)$. According to the findings of the present study, the connection between involvement in resistance training and body composition in women is not influenced by whether or not a high or a low protein diet is consumed.

Like strength training, physical activity tends to promote leanness. ${ }^{75-77}$ Therefore, studies that do not adjust for differences in physical activity are likely ignoring a key confounding variable. The present study appears to be the first study to quantify the effect of objectively measured physical activity on the strength training and body composition association.

In the present investigation, women who engaged the most in strength training also tended to be the most physically active. As shown in Table 1, the difference in objectively measured physical activity between the Lifters and Nonlifters over the $7 \mathrm{~d}$ of monitoring was approximately 581,500 activity counts, a difference equivalent to approximately $145 \mathrm{~min}$ of walking (3-4 mph) over the week. ${ }^{78,79}$ 
Individually adjusting for differences in objectively measured physical activity had the greatest effect on the lifting and body composition relationships, weakening them by $44-68 \%$. Evidently, a large portion of the strength training and body composition relationship is due to differences in physical activity. In short, if all women had equal physical activity levels, the relationship between strength training and body composition would be weaker, but still significant and meaningful.

Results from the present study are similar to findings from a cross-sectional investigation by Trudelle-Jackson et al. ${ }^{80}$ After controlling for age, race, and self-reported physical activity, women who met the strength training recommendations of 2 or more $\mathrm{d}$ per week were more likely to have a lower body fat percentage and less likely to be classified as obese, compared to women who did not meet the recommendations.

Regarding the frequency of strength training per week, findings from the present study coincide with results reported by Marx et al..$^{23}$ who investigated the effect of different training volumes on 34 untrained females. Percent body fat significantly decreased among subjects assigned to a high-volume, 4-days-per-week training plan compared to participants assigned to the control or low-volume ( $3 \mathrm{~d}$ per week) groups. Furthermore, after 24 weeks of strength training, a significant increase in fat-free mass was only observed in the high-volume group compared to the control and low-volume groups.

Findings from the present study are also in agreement with the investigation by Bea et al. ${ }^{37}$ In the Bea et al. investigation, resistance training frequency tended to be predictive of change in body fat and attenuated age-related losses in fat-free mass among postmenopausal women who strength trained 2 to $3 \mathrm{~d}$ per week. Subjects were followed for $6 \mathrm{y}$. 
In contrast, findings of the present study conflict with the results of Benton et al. ${ }^{81}$ regarding the effect of strength training frequency on body composition. In the Benton et al. study, lifting 4 versus $3 \mathrm{~d}$ per week did not lead to a significant difference in percent body fat or fat-free mass among subjects after holding weekly training volumes constant. However, unlike the Marx et al. ${ }^{23}$ study, no control group was utilized in Benton's et al. study.

Contradicting findings of the present study, Schroeder et al. ${ }^{31}$ identified no significant change in fat-free mass when comparing the effects of high- and low-intensity training programs in previously untrained young women. While both intervention groups significantly increased in fat-free mass compared to baseline levels, the low-intensity group also significantly increased in absolute fat mass.

Findings from two randomized controlled trials of $1 \mathrm{y}$ or longer also support the present results. Schmitz et al. ${ }^{35}(\mathrm{n}=164)$ and Olson et al. ${ }^{82}(\mathrm{n}=28)$ identified a significant increase in fat-free mass among untrained, premenopausal females who lifted $2 \mathrm{~d}$ per week. Similar strength training interventions were employed in both studies. Physical activity was measured and remained constant throughout each study. The effect of physical activity on the strength training and body composition relationship was not quantified, however.

In Schmitz's et al. ${ }^{35}$ investigation, diet and physical activity levels were measured via the National Institute of Health's Diet History Questionnaire (DHQ) and accelerometry, respectively. A significant decrease in body fat percentage was observed in resistance trained participants compared to controls. Furthermore, Schmitz et al. ${ }^{35}$ reported no significant increase in fat-free mass following the $2 \mathrm{y}$ of resistance training. Lack of adherence to the study protocol may have been a factor. 
Olson et al.$^{82}$ identified a significant increase in fat-free mass in the treatment group compared to the control group. However, no significant change in body fat percentage was observed when comparing the control and intervention groups. Physical activity was tracked using exercise logs. Also, subjects were asked to not change their normal dietary patterns. However, diet was not measured throughout the study.

Weaknesses of the present study include its cross-sectional design and homogeneous sample. Due to its cross-sectional nature, causal relationships may not be surmised. Additionally, the sample consisted primarily of middle-aged, nonsmoking, Caucasian females. Therefore, generalization of the results derived from the present study is limited to similar populations.

A major strength of the current investigation was the use of high-quality measurement methods to adjust for and quantify the effect of numerous potential confounders, including age, menopause status, energy consumption, protein intake, and measured physical activity. Accelerometry was used to objectively assess physical activity rather than self-report, and DXA was employed to assess body composition, as opposed to skinfold calipers, bioelectrical impedance, or plethysmography. Moreover, instead of using a food frequency questionnaire, 7-d weighed food records were used to determine dietary intake, thus limiting the error associated with recall and portion size estimates.

In summary, several significant linear relationships between level of involvement in strength training and body composition were identified in the present study. After controlling simultaneously for differences in age, menopause status, energy consumption, protein intake, and physical activity, statistical significance remained for virtually every relationship between strength training and body composition. Individually adjusting for differences in objectively measured physical activity weakened the strength training and body composition relationships 
substantially, but all of the associations remained significant except for the relationship between consecutive years of strength training and fat-free mass. Consequently, differences in body composition among middle-age women who strength train regularly and those who do not appear to be partly a function of differing physical activity levels.

In conclusion, women who strength train regularly tend to have significantly lower body fat percentages and significantly higher levels of fat-free mass compared to their counterparts. Hence, women who do not strength train habitually may have higher levels of morbidity and mortality compared to those who train regularly. ${ }^{10,12}$ Moreover, future investigations may benefit by paying close attention to the physical activity levels of participants in strength training programs because of the significant effect physical activity had on the outcomes of this study. Given the dose-response relationships uncovered in the present investigation, it appears that the more time and the more effort women invest in strength training, the more favorable their body composition tends to be. 


\section{References}

1. Bushman B, Batista R. ACSM's Resources for the Personal Trainer. 4th ed. China: Wolters Kluwer - Lippincott Williams \& Wilkins; 2014.

2. Botero JP, Shiguemoto GE, Prestes J, Marin CT, Do Prado WL, Pontes CS, et al. Effects of long-term periodized resistance training on body composition, leptin, resistin and muscle strength in elderly post-menopausal women. $J$ Sports Med Phys Fitness. 2013;53(3):289-294.

3. Dishman RK, Heath GW, Lee I-M. Physical Activity Epidemiology. 2nd ed. United States of America: Human Kinetics; 2013.

4. Heitmann BL, Erikson H, Ellsinger BM, Mikkelsen KL, Larsson B. Mortality associated with body fat, fat-free mass and body mass index among 60 -year-old swedish men-a 22year follow-up. Int J Obes Relat Metab Disord. 2000;24(1):33-37.

5. Lahmann PH, Lissner L, Gullberg B, Berglund GA. prospective study of adiposity and all-cause mortality: the Malmo Diet and Cancer Study. Obes Res. 2002;10(5):361-369.

6. Romero-Corral A, Somers VK, Sierra-Johnson J, Korenfeld Y, Boarin S, Korinek J, et al. Normal weight obesity: a risk factor for cardiometabolic dysregulation and cardiovascular mortality. Eur Heart J. 2010;31(6):737-746.

7. Batsis JA, Singh S, Lopez-Jimenez F. Anthropometric measurements and survival in older americans: results from the third national health and nutrition examination survey. $J$ Nutr Health Aging. 2014;18(2):123-130.

8. Miller JP, Pratley RE, Goldberg AP, Gordon P, Rubin M, Treuth MS, et al. Strength training increases insulin action in healthy 50- to 65-yr-old men. J Appl Physiol. 1994;77(3):1122-1127. 
9. Hurley BF, Hagberg JM, Goldberg AP, Seals DR, Ehsani AA, Brennan RE, et al. Resistive training can reduce coronary risk factors without altering VO2max or percent body fat. Med Sci Sports Exerc. 1988;20(2):150-154.

10. Braith RW, Stewart KJ. Resistance exercise training: its role in the prevention of cardiovascular disease. Circulation. 2006;113(22):2642-2650.

11. Poehlman ET, Denino WF, Beckett T, Kinaman KA, Dionne IJ, Dvorak R, et al. Effects of endurance and resistance training on total daily energy expenditure in young women: a controlled randomized trial. J Clin Endocrinol Metab. 2002;87(3):1004-1009.

12. Fletcher GF, Balady G, Blair SN, Blumenthal J, Caspersen C, Chaitman B, et al. Statement on exercise: benefits and recommendations for physical activity programs for all Americans. A statement for health professionals by the Committee on Exercise and Cardiac Rehabilitation of the Council on Clinical Cardiology, American Heart Association. Circulation. 1996;94(4):857-862.

13. Klein S, Burke LE, Bray GA, Blair S, Allison DB, Pi-Sunyer X, et al. Clinical implications of obesity with specific focus on cardiovascular disease: a statement for professionals from the American Heart Association Council on Nutrition, Physical Activity, and Metabolism: endorsed by the American College of Cardiology Foundation. Circulation. 2004;110(18):2952-2967.

14. Muller MJ, Geisler C, Pourhassan M, Gluer CC, Bosy-Westphal A. Assessment and definition of lean body mass deficiency in the elderly. Eur J Clin Nutr. 2014;68(11):1220-1227. 
15. Stenholm S, Harris TB, Rantanen T, Visser M, Kritchevsky SB, Ferrucci L. Sarcopenic obesity: definition, cause and consequences. Curr Opin Clin Nutr Metab Care. 2008;11(6):693-700.

16. Williams MA, Haskell WL, Ades PA, Amsterdam EA, Bittner V, Franklin BA, et al. Resistance exercise in individuals with and without cardiovascular disease: 2007 update: a scientific statement from the American Heart Association Council on Clinical Cardiology and Council on Nutrition, Physical Activity, and Metabolism. Circulation. 2007;116(5):572-584.

17. McCarthy JP, Agre JC, Graf BK, Pozniak MA, Vailas AC. Compatibility of adaptive responses with combining strength and endurance training. Med Sci Sports Exerc. 1995;27(3):429-436.

18. Hunter GR, Wetzstein CJ, Fields DA, Brown A, Bamman MM. Resistance training increases total energy expenditure and free-living physical activity in older adults. $J \mathrm{Appl}$ Physiol. 2000;89(3):977-984.

19. Hunter GR, McCarthy JP, Bamman MM. Effects of resistance training on older adults. Sports Med. 2004;34(5):329-348.

20. Kim JS, Cross JM, Bamman MM. Impact of resistance loading on myostatin expression and cell cycle regulation in young and older men and women. Am J Physiol Endocrinol Metab. 2005;288(6):E1110-1119.

21. Pollock ML, Gaesser GA, Butcher JD, Despres J-P, Dishman RK, Franklin BA, et al. ACSM Position Stand: The Recommended Quantity and Quality of Exercise for Developing and Maintaining Cardiorespiratory and Muscular Fitness, and Flexibility in Healthy Adults. Med Sci Sports Exerc. 1998;30(6):975-991. 
22. Galuska DA, Earle D, Fulton JE. The epidemiology of U.S. adults who regularly engage in resistance training. Res $Q$ Exerc Sport. 2002;73(3):330-334.

23. Marx JO, Ratamess NA, Nindl BC, Gotshalk LA, Volek JS, Dohi K, et al. Low-volume circuit versus high-volume periodized resistance training in women. Med Sci Sports Exerc. 2001;33(4):635-643.

24. Washburn RA, Kirk, EP, Smith BK, Honas JJ, Lecheminant JD, Bailey BW, et al. One set resistance training: effect on body composition in overweight young adults. $J$ Sports Med Phys Fitness. 2012;53(3):273-279.

25. Mayhew JL, Gross PM Body composition changes in young women with high resistance weight training. Res $Q .1974 ; 45(4): 433-440$.

26. Nichols JF, Omizo DK, Peterson KK, Nelson KP. Efficacy of heavy-resistance training for active women over sixty: muscular strength, body composition, and program adherence. J Am Geriatr Soc. 1993;41(3):205-210.

27. Poehlman ET, Dvorak RV, DeNino WF, Brochu M, Ades PA. Effects of resistance training and endurance training on insulin sensitivity in nonobese, young women: a controlled randomized trial. J Clin Endocrinol Metab. 2000;85(7):2463-2468.

28. de Lima C, Boullosa DA, Frollini AB, Donatto FF, Leite RD, Gonelli PR, et al. Linear and daily undulating resistance training periodizations have differential beneficial effects in young sedentary women. Int J Sports Med. 2012;33(9):723-727.

29. Prabhakaran B, Dowling EA, Branch JD, Swain DP, Leutholtz BC. Effect of 14 weeks of resistance training on lipid profile and body fat percentage in premenopausal women. $\mathrm{Br}$ J Sports Med. 1999;33(3):190-195. 
30. Conceicao MS, Bonganha V, Vechin FC, Berton RP, Lixandrao ME, Nogueira FR, et al. Sixteen weeks of resistance training can decrease the risk of metabolic syndrome in healthy postmenopausal women. Clin Interv Aging. 2013;8:1221-1228.

31. Schroeder ET, Hawkins SA, Jaque SV. Musculoskeletal adaptations to 16 weeks of eccentric progressive resistance training in young women. $J$ Strength Cond Res. 2004;18(2):227-235.

32. Sillanpaa E, Laaksonen DE, Hakkinen A, Karavirta L, Jensen B, Kraemer WJ, et al. Body composition, fitness, and metabolic health during strength and endurance training and their combination in middle-aged and older women. Eur J Appl Physiol. 2009;106(2):285-296.

33. Orsatti FL, Nahas EA, Maesta N, Nahas-Neto J, Burini RC. Plasma hormones, muscle mass and strength in resistance-trained postmenopausal women. Maturitas. 2008;59(4):394-404 .

34. Kemmler WK, Lauber D, Engelke K, Weineck J. Effects of single- vs. multiple-set resistance training on maximum strength and body composition in trained postmenopausal women. $J$ Strength Cond Res. 2004;18(4):689-694.

35. Schmitz KH, Hannan PJ, Stovitz SD, Bryan CJ, Warren M, Jensen MD. Strength training and adiposity in premenopausal women: strong, healthy, and empowered study. The Am J Clin Nutr. 2007;86(3):566-572.

36. Warren M, Petit MA, Hannan PJ, Schmitz KH. Strength training effects on bone mineral content and density in premenopausal women. Med Sci Sports Exerc. 2008;40(7):12821288. 
37. Bea JW, Cussler EC, Going SB, Blew RM, Metcalfe LL, Lohman TG. Resistance Training Predicts Six-Year Body Composition Change in Postmenopausal Women. Med Sci Sports Exerc. 2010;42(7):1286-1295.

38. Haskell WL, Lee IM, Pate RR, Powell KE, Blair SN, Franklin BA, et al. Physical activity and public health: updated recommendation for adults from the American College of Sports Medicine and the American Heart Association. Circulation. 2007;116(9):10811093.

39. Assah FK, Ekelund U, Brage S, Corder K, Wright A, Mbanya JC, et al. Predicting physical activity energy expenditure using accelerometry in adults from sub-Sahara Africa. Obesity. 2009;17(8):1588-1595.

40. Koster A, Caserotti P, Patel KV, Matthews CE, Berrigan D, Van Domelen DR, et al. Association of sedentary time with mortality independent of moderate to vigorous physical activity. PloS one. 2012;7(6):e37696.

41. Trost SG, McIver KL, Pate RR. Conducting accelerometer-based activity assessments in field-based research. Med Sci Sports Exerc. 2005;37(11 Suppl):S531-543.

42. Troiano RP, Berrigan D, Dodd KW, Masse LC, Tilert T, McDowell M. Physical activity in the United States measured by accelerometer. Med Sci Sports Exerc. 2008;40(1):181188.

43. Jerome GJ, Young DR, Laferriere D, Chen C, Vollmer WM. Reliability of RT3 accelerometers among overweight and obese adults. Med Sci Sports Exerc. 2009;41(1):110-114. 
44. LaPorte RE, Montoye HJ, Caspersen CJ. Assessment of physical activity in epidemiologic research: problems and prospects. Public Health Rep. 1985;100(2):131146.

45. Liu AL, Li YP, Song J, Pan H, Han XM, Ma GS. Study on the validation of the computer science application's activity monitor in assessing the physical activity among adults using doubly labeled water method. Zhonghua Liu Xing Bing Xue Za Zhi. 2005;26(3):197-200.

46. Bassett DR, Jr., Ainsworth BE, Swartz AM, Strath SJ, O'Brien WL, King GA. Validity of four motion sensors in measuring moderate intensity physical activity. Med Sci Sports Exerc. 2000;32(9 Suppl):S471-480.

47. Welk GJ, Schaben JA, Morrow JR, Jr. Reliability of accelerometry-based activity monitors: a generalizability study. Med Sci Sports Exerc. 2004;36(9):1637-1645.

48. Brage S, Wedderkopp N, Franks PW, Andersen LB, Froberg K. Reexamination of validity and reliability of the CSA monitor in walking and running. Med Sci Sports Exerc. $2003 ; 35(8): 1447-1454$.

49. Hartman AM, Brown CC, Palmgren J, Pietinen P, Verkasalo M, Myer D, et al. Variability in nutrient and food intakes among older middle-aged men. Implications for design of epidemiologic and validation studies using food recording. Am J Epidemiol. 1990;132(5):999-1012.

50. Buzzard M. 24-hour dietary recall and food record methods. Monographs in Epidemiology and Biostatistics. 1998:50-73.

51. Goldberg G, Black A, Jebb S, Cole TJ, Murgatroyd PR, Coward WA, et al. Critical evaluation of energy intake data using fundamental principles of energy physiology: 1. 
Derivation of cut-off limits to identify under-recording. Eur J Clin Nutr. 1991;45(12):569-581.

52. Ravussin E, Lillioja S, Anderson TE, Christin L, Bogardus C. Determinants of 24-hour energy expenditure in man. Methods and results using a respiratory chamber. $J$ Clin Invest. 1986;78(6):1568-1578.

53. Tucker LA, Nokes NR, Bailey BW, Lecheminant JD. Cardiorespiratory fitness and hip bone mineral density in women: a 6-year prospective study. Percept Mot Skills. 2014;119(2):333-346.

54. Laskey MA. Dual-energy X-ray absorptiometry and body composition. Nutrition. 1996;12(1):45-51.

55. Pritchard JE, Nowson CA, Strauss BJ, Carlson JS, Kaymakci B, Wark JD. Evaluation of dual energy X-ray absorptiometry as a method of measurement of body fat. Eur J Clin Nutr. 1993;47(3):216-228.

56. Mazess RB, Barden HS, Bisek JP, Hanson J. Dual-energy X-ray absorptiometry for totalbody and regional bone-mineral and soft-tissue composition. Am J Clin Nutr. 1990;51(6):1106-1112.

57. Maddalozzo GF, Cardinal BJ, Snow CA. Concurrent validity of the BOD POD and dual energy X-ray absorptiometry techniques for assessing body composition in young women. J Am Diet Assoc. 2002;102(11):1677-1679.

58. Genton L, Karsegard VL, Zawadynski S, Kyle UG, Pichard C, Golay A, et al. Comparison of body weight and composition measured by two different dual energy Xray absorptiometry devices and three acquisition modes in obese women. Clin Nutr. 2006;25(3):428-437. 
59. Lukaski HC. Soft tissue composition and bone mineral status: evaluation by dual-energy X-ray absorptiometry. J Nutr. 1993;123(2 Suppl):438-443.

60. Wang J, Heymsfield SB, Aulet M, Thornton JC, Pierson RN, Jr. Body fat from body density: underwater weighing vs. dual-photon absorptiometry. Am J Physiol. 1989;256(6 Pt 1):E829-834.

61. Rothman KJ. BMI-related errors in the measurement of obesity. Int J Obes (Lond). 2008;32 Suppl 3:S56-59.

62. LeCheminant JD, Tucker LA, Peterson TR, Bailey BW. Differences in body fat percentage measured using dual energy X-ray absorptiometry and the Bod Pod in 100 women. Med Sci Sports Exerc. 2001;33(5):S174.

63. Golding LA, Myers CR, Sinning WE. Y's Way to Physical Fitness: The Complete Guide to Fitness Testing and Instruction. 3rd ed. Champaign, IL: Published for YMCA of the USA by Human Kinetics Publishers. 1989.

64. Taylor J, Tucker LA. Comparison of the CardioGlide, CrossWalk, and treadmill walking in development of cardiovascular endurance, dynamic strength, and flexibility in middleaged men and women. Percept Mot Skills. 1996;82(3):875-882.

65. American Council on Exercise. ACE Personal Trainer Manual : The Ultimate Resource for Fitness Professionals. 3rd ed. San Diego, CA: American Council on Exercise. 2003.

66. Leard JS, Cirillo MA, Katsnelson E, Kimiatek DA, Miller TW, Trebincevic K, et al. Validity of two alternative systems for measuring vertical jump height. J Strength Cond Res. 2007;21(4):1296-1299. 
67. Trevisan M, Burini RC. Resting metabolism of post-menopause women submitted to a training program with weights (hypertrophy). Rev Bras Med Esporte. 2007;13(2):116e$119 \mathrm{e}$.

68. Bouchard C, Tremblay A, Despres JP, Nadeau A, Lupien PJ, Theriault G, et al. The response to long-term overfeeding in identical twins. N Engl J Med. 1990;322(21):14771482.

69. Horton TJ, Drougas H, Brachey A, Reed GW, Peters JC, Hill JO. Fat and carbohydrate overfeeding in humans: different effects on energy storage. Am J Clin Nutr. 1995;62(1):19-29.

70. Bray GA, Smith SR, de Jonge L, Xie H, Rood J, Martin CK, et al. Effect of dietary protein content on weight gain, energy expenditure, and body composition during overeating: a randomized controlled trial. JAMA. 2012;307(1):47-55.

71. Areta JL, Burke LM, Ross ML, Camera DM, West DW, Broad EM, et al. Timing and distribution of protein ingestion during prolonged recovery from resistance exercise alters myofibrillar protein synthesis. $J$ Physiol. 2013;591(Pt 9):2319-2331.

72. Moore DR, Areta J, Coffey VG, Stellingwerff T, Phillips SM, Burke LM, et al. Daytime pattern of post-exercise protein intake affects whole-body protein turnover in resistancetrained males. Nutr Metab (Lond). 2012;9(1):91.

73. Burd NA, Yang Y, Moore DR, Tang JE, Tarnopolsky MA, Phillips SM. Greater stimulation of myofibrillar protein synthesis with ingestion of whey protein isolate $\mathrm{v}$. micellar casein at rest and after resistance exercise in elderly men. Br J Nutr. 2012;108(6):958-962. 
74. Yang Y, Churchward-Venne TA, Burd NA, Breen L, Tarnopolsky MA, Phillips SM. Myofibrillar protein synthesis following ingestion of soy protein isolate at rest and after resistance exercise in elderly men. Nutr Metab (Lond). 2012;9(1):57.

75. Bailey BW, Borup P, LeCheminant JD, Tucker LA, Bromley J. Examining the Relationship Between Physical Activity Intensity and Adiposity in Young Women. $J$ Phys Act Health. 2014;12(6):764-769.

76. Bailey BW, Tucker LA, Peterson TR, LeCheminant JD. A prospective study of physical activity intensity and change in adiposity in middle-aged women. Am J Health Promot. 2007;21(6):492-497.

77. Tucker L, Peterson T. Fitness level and risk of weight gain in middle-age women: a prospective cohort study. $J$ Phys Act Health. 2010;7(3):308-315.

78. Nokes NR, Tucker LA. Changes in hip bone mineral density and objectively measured physical activity in middle-aged women: a 6-year prospective study. Am J Health Promot. 2012;26(6):341-347.

79. Breneman CB, Tucker L. Dietary fibre consumption and insulin resistance - the role of body fat and physical activity. Br J Nutr. 2013;110(2):375-383.

80. Trudelle-Jackson E, Jackson AW, Morrow JR, Jr. Relations of meeting national public health recommendations for muscular strengthening activities with strength, body composition, and obesity: the Women's Injury Study. Am J Public Health. 2011;101(10):1930-1935.

81. Benton MJ, Kasper MJ, Raab SA, Waggener GT, Swan PD. Short-term effects of resistance training frequency on body composition and strength in middle-aged women. $J$ Strength Cond Res. 2011;25(11):3142-3149. 
82. Olson TP, Dengel DR, Leon AS, Schmitz KH. Changes in inflammatory biomarkers following one-year of moderate resistance training in overweight women. Int J Obes (Lond). 2007;31(6):996-1003. 
Table 1 Descriptive statistics between all subjects and mean differences between Lifters and Nonlifters

\begin{tabular}{|c|c|c|c|c|c|c|c|c|}
\hline \multirow[b]{2}{*}{ Variables } & \multicolumn{2}{|c|}{$\begin{array}{l}\text { All Subjects } \\
\mathrm{n}=257\end{array}$} & \multicolumn{2}{|c|}{$\begin{array}{c}\text { Lifters } \\
n=109\end{array}$} & \multicolumn{2}{|c|}{$\begin{array}{c}\text { Nonlifters } \\
\mathrm{n}=148\end{array}$} & \multirow[b]{2}{*}{$\mathrm{F}$} & \multirow[b]{2}{*}{$\mathrm{P}$} \\
\hline & Mean & SD & Mean & SD & Mean & SD & & \\
\hline$\overline{\text { Age }}$ & 41.7 & 3.0 & 41.6 & 3.0 & 41.7 & 3.0 & 0.1 & 0.7505 \\
\hline Weight (kg) & 64.8 & 10.5 & 63.8 & 10.0 & 65.6 & 10.8 & 1.8 & 0.1788 \\
\hline Body fat (\%) & 32.3 & 7.2 & 30.1 & 6.8 & 34.0 & 7.1 & 19.3 & $<0.0001$ \\
\hline Fat-free mass $(\mathrm{kg})^{*}$ & 44.0 & 5.1 & 45.0 & 5.0 & 43.3 & 5.2 & 20.4 & $<0.0001$ \\
\hline Total energy intake (kcal) & 1974.5 & 316.0 & 1963.5 & 309.3 & 1982.7 & 321.7 & 0.2 & 0.6306 \\
\hline Energy intake (kcal/kg) & 31.0 & 5.7 & 31.3 & 6.0 & 30.7 & 5.5 & 0.6 & 0.4305 \\
\hline Protein intake $(\%)$ & 14.4 & 3.0 & 15.0 & 3.3 & 14.1 & 2.7 & 5.7 & 0.0181 \\
\hline Physical activity (counts) $\dagger$ & 2648.9 & 925.2 & 2983.8 & 939.2 & 2402.3 & 835.7 & 27.3 & $<0.0001$ \\
\hline Lifting: days per week & 1.0 & 1.3 & 2.4 & 0.7 & 0 & 0 & 1941.3 & $<0.0001$ \\
\hline Lifting: minutes per session & 14.5 & 20.0 & 34.2 & 16.4 & 0 & 0 & 645.2 & $<0.0001$ \\
\hline Lifting: intensity of sessions & 2.9 & 3.5 & 6.7 & 1.9 & 0 & 0 & 1762.1 & $<0.0001$ \\
\hline Lifting: total time per week (min) & 34.8 & 49.7 & 82.1 & 44.0 & 0 & 0 & 517.3 & $<0.0001$ \\
\hline Lifting: years & 1.1 & 2.2 & 2.7 & 2.7 & 0 & 0 & 142.4 & $<0.0001$ \\
\hline
\end{tabular}

The F- and the P-values refer to the statistical comparison of the Lifters and the Nonlifters.

Menopause status was a categorical variable and was treated as a potential confounding variable. Of the Nonlifters, $33 \%$ were post-menopausal, whereas $18 \%$ of Lifters were post-menopausal $\left(\chi^{2}=6.96, p=0.0083\right)$.

As noted in the Methods section, Lifters included women who reported that they strength train regularly at least $1 \mathrm{~d}$ per week, whereas Nonlifters included participants who strength train $<1 \mathrm{~d}$ per week.

* When comparing Lifters and Nonlifters on fat-free mass, total body mass was controlled statistically.

$\dagger$ Weekly activity counts were divided by 1000 to make the values for this table more manageable. 
Table 2 Differences in body fat percentage and fat-free mass corresponding to a 1-day-per-week difference in strength training, independent of key potential confounding variables $(n=257)$

Body Fat (\%)

Fat-Free Mass (g)

\begin{tabular}{lccccccccc}
$\begin{array}{l}\text { Differences in body fat } \\
\text { and fat-free mass }\end{array}$ & $\begin{array}{l}\text { Regression } \\
\text { Coefficient }\end{array}$ & SE & F & P & $\begin{array}{l}\text { Regression } \\
\text { Coefficient }\end{array}$ & SE & F & P \\
\hline Variable controlled: & & & & & & & & & \\
None* & -1.32 & 0.34 & 14.8 & 0.0002 & 656.37 & 151.13 & 18.9 & $<0.0001$ \\
Age & -1.32 & 0.34 & 14.9 & 0.0001 & 656.20 & 150.29 & 19.1 & $<0.0001$ \\
Menopause status & -1.15 & 0.34 & 11.3 & 0.0009 & 598.30 & 151.67 & 15.6 & 0.0001 \\
Total energy intake & -1.21 & 0.28 & 18.9 & $<0.0001$ & 656.80 & 144.77 & 20.6 & $<0.0001$ \\
Total physical activity & -0.81 & 0.34 & 5.5 & 0.0196 & 468.85 & 153.55 & 9.3 & 0.0025 \\
Protein intake & -1.34 & 0.35 & 14.6 & 0.0002 & 648.07 & 154.46 & 17.6 & $<0.0001$ \\
All covariates & -0.85 & 0.30 & 8.3 & 0.0044 & 443.33 & 154.06 & 8.3 & 0.0044
\end{tabular}

*In the fat-free mass model, body weight was always controlled statistically.

Interpretation of the results would be as follows: For body fat (\%), after adjusting for differences in protein intake, for each additional day per week participants strength trained, they had 1.34 percentage points lower body fat, on average. 
Table 3 Differences in body fat percentage and fat-free mass corresponding to a 10-min difference in total time spent strength training per session, independent of key potential confounding variables $(\mathrm{n}=257)$

\begin{tabular}{|c|c|c|c|c|c|c|c|c|}
\hline \multirow{3}{*}{$\begin{array}{l}\text { Differences in body } \\
\text { fat and fat-free mass }\end{array}$} & \multicolumn{4}{|c|}{ Body Fat (\%) } & \multicolumn{4}{|c|}{ Fat-Free Mass (g) } \\
\hline & Regression & & & & Regression & & & \\
\hline & Coefficient & SE & $\mathrm{F}$ & $\mathrm{P}$ & Coefficient & SE & $\mathrm{F}$ & $\mathrm{P}$ \\
\hline \multicolumn{9}{|l|}{ Variable controlled: } \\
\hline None* & -0.96 & 0.22 & 19.6 & $<0.0001$ & 413.85 & 97.22 & 18.1 & $<0.0001$ \\
\hline Age & -0.95 & 0.22 & 19.3 & $<0.0001$ & 409.89 & 96.78 & 17.9 & $<0.0001$ \\
\hline Menopause status & -0.85 & 0.22 & 15.3 & 0.0001 & 375.35 & 97.67 & 14.8 & 0.0002 \\
\hline Total energy intake & -0.80 & 0.18 & 20.0 & $<0.0001$ & 399.45 & 93.45 & 18.3 & $<0.0001$ \\
\hline Total physical activity & -0.70 & 0.22 & 10.7 & 0.0012 & 314.67 & 96.69 & 10.6 & 0.0013 \\
\hline Protein intake & -0.98 & 0.22 & 19.5 & $<0.0001$ & 408.54 & 99.49 & 16.9 & $<0.0001$ \\
\hline All covariates & -0.59 & 0.19 & 10.0 & 0.0018 & 272.39 & 97.00 & 7.9 & 0.0054 \\
\hline
\end{tabular}

*In the fat-free mass model, body weight was always controlled statistically.

Interpretation of the results would be as follows: For fat-free mass (g), after adjusting for differences in age (and body weight), for each additional $10 \mathrm{~min}$ in total time spent strength training per session, participants had 409.89 grams more fat-free mass, on average. 
Table 4 Differences in body fat percentage and fat-free mass corresponding to a 10-min difference in total time spent strength training per week, independent of key potential confounding variables $(\mathrm{n}=257)$

Body Fat $(\%)$

\begin{tabular}{|c|c|c|c|c|c|c|c|c|}
\hline \multirow{2}{*}{$\begin{array}{l}\text { Differences in body fat } \\
\text { and fat-free mass }\end{array}$} & \multicolumn{4}{|l|}{ Regression } & \multicolumn{4}{|l|}{ Regression } \\
\hline & Coefficient & SE & $\mathrm{F}$ & $\mathrm{P}$ & Coefficient & SE & $\mathrm{F}$ & $\mathrm{P}$ \\
\hline \multicolumn{9}{|l|}{ Variable controlled: } \\
\hline None* & -0.34 & 0.09 & 14.3 & 0.0002 & 157.44 & 39.17 & 16.2 & $<0.0001$ \\
\hline Age & -0.33 & 0.09 & 14.3 & 0.0002 & 156.61 & 38.97 & 16.2 & $<0.0001$ \\
\hline Menopause status & -0.29 & 0.09 & 10.4 & 0.0014 & 140.60 & 39.48 & 12.7 & 0.0004 \\
\hline Total energy intake & -0.29 & 0.07 & 15.6 & 0.0001 & 152.98 & 37.63 & 16.5 & $<0.0001$ \\
\hline Total physical activity & -0.23 & 0.09 & 7.3 & 0.0074 & 119.38 & 38.76 & 9.5 & 0.0023 \\
\hline Protein intake & -0.35 & 0.09 & 14.4 & 0.0002 & 156.51 & 40.62 & 14.9 & 0.0001 \\
\hline All covariates & -0.20 & 0.08 & 6.7 & 0.0103 & 101.31 & 39.60 & 6.5 & 0.0111 \\
\hline
\end{tabular}

Fat-Free Mass (g)

*In the fat-free mass model, body weight was always controlled statistically.

Interpretation of the results would be as follows: For body fat (\%), after adjusting for differences in total physical activity, for each additional $10 \mathrm{~min}$ in total time spent strength training per week, participants had 0.23 percentage point lower body fat, on average. 
Table 5 Differences in body fat percentage and fat-free mass corresponding to a $1 \mathrm{y}$ difference in years of continuous strength training, independent of key potential confounding variables $(n=257)$

\begin{tabular}{|c|c|c|c|c|c|c|c|c|}
\hline \multirow{3}{*}{$\begin{array}{l}\text { Differences in body fat } \\
\text { and fat-free mass }\end{array}$} & \multicolumn{4}{|c|}{ Body Fat (\%) } & \multicolumn{4}{|c|}{ Fat-Free Mass (g) } \\
\hline & Regression & & & & Regression & & & \\
\hline & Coefficient & $\mathrm{SE}$ & $\mathrm{F}$ & $\mathrm{P}$ & Coefficient & SE & $\mathrm{F}$ & $\mathrm{P}$ \\
\hline \multicolumn{9}{|l|}{ Variable controlled: } \\
\hline None* & -0.65 & 0.20 & 10.4 & 0.0015 & 270.05 & 89.64 & 9.1 & 0.0029 \\
\hline Age & -0.64 & 0.20 & 10.4 & 0.0014 & 269.68 & 89.17 & 9.2 & 0.0027 \\
\hline Menopause status & -0.59 & 0.20 & 8.9 & 0.0032 & 251.01 & 88.71 & 8.0 & 0.0050 \\
\hline Total energy intake & -0.58 & 0.16 & 12.8 & 0.0004 & 277.83 & 85.93 & 10.5 & 0.0014 \\
\hline Total physical activity & -0.38 & 0.20 & 3.6 & 0.0582 & 166.57 & 89.30 & 3.5 & 0.0633 \\
\hline Protein intake & -0.65 & 0.20 & 10.1 & 0.0016 & 262.29 & 90.26 & 8.4 & 0.0040 \\
\hline All covariates & -0.41 & 0.17 & 6.0 & 0.0147 & 169.60 & 86.99 & 3.8 & 0.0523 \\
\hline
\end{tabular}

* In the fat-free mass model, body weight was always controlled statistically.

Interpretation of the results would be as follows: For fat-free mass (g), after adjusting for differences in total energy intake (and body weight), for each additional year of strength training, participants had 277.83 grams more fat-free mass, on average. 
Table 6 Differences in body fat percentage and fat-free mass corresponding to a 1-unit difference in intensity of strength training sessions, independent of key potential confounding variables $(n=257)$

\begin{tabular}{|c|c|c|c|c|c|c|c|c|}
\hline \multirow{3}{*}{$\begin{array}{l}\text { Differences in body fat } \\
\text { and fat-free mass }\end{array}$} & \multicolumn{4}{|c|}{ Body Fat (\%) } & \multicolumn{4}{|c|}{ Fat-Free Mass (g) } \\
\hline & Regression & & & & Regression & & & \\
\hline & Coefficient & SE & $\mathrm{F}$ & $\mathrm{P}$ & Coefficient & SE & $\mathrm{F}$ & $\mathrm{P}$ \\
\hline \multicolumn{9}{|l|}{ Variable controlled: } \\
\hline None* & -0.57 & 0.12 & 21.4 & $<0.0001$ & 280.01 & 54.16 & 26.7 & $<0.0001$ \\
\hline Age & -0.55 & 0.12 & 19.9 & $<0.0001$ & 272.48 & 54.25 & 25.2 & $<0.0001$ \\
\hline Menopause status & -0.51 & 0.12 & 17.3 & $<0.0001$ & 260.21 & 54.37 & 22.9 & $<0.0001$ \\
\hline Total energy intake & -0.51 & 0.10 & 26.0 & $<0.0001$ & 276.54 & 51.89 & 28.4 & $<0.0001$ \\
\hline Total physical activity & -0.40 & 0.12 & 10.6 & 0.0013 & 218.72 & 54.83 & 15.9 & $<0.0001$ \\
\hline Protein intake & -0.59 & 0.13 & 21.5 & $<0.0001$ & 279.97 & 55.63 & 25.3 & $<0.0001$ \\
\hline All covariates & -0.38 & 0.11 & 12.4 & 0.0005 & 200.77 & 55.53 & 13.1 & 0.0004 \\
\hline
\end{tabular}

* In the fat-free mass model, body weight was always controlled statistically.

Interpretation of the results would be as follows: For body fat (\%), after adjusting for differences in all of the covariates simultaneously, for every 1-unit increase in self-reported training intensity, participants had 0.38 percentage point lower body fat, on average. 